\title{
ANALISIS KECACATAN PRODUK BLOCK CYLINDER DENGAN MENGGUNAKAN PETA KENDALI
}

\author{
R.M.B. Agung E.W. ${ }^{1}$, Akhmad Syarief ${ }^{1}$, Agustina Hotma Uli Tumanggor ${ }^{2}$ \\ ${ }^{1}$ Jurusan Teknik Mesin, Fakultas Teknik, Universitas Lambung Mangkurat \\ ${ }^{2}$ Jurusan Teknik Industri, Fakultas Sains dan Teknologi, Universitas Sari Mulia \\ ${ }^{1}$ Jl. Achmad Yani Km. 32 Banjarbaru Kalimantan Selatan \\ ${ }^{2} J$ l. Pramuka No. 2 Banjarmasin Kalimantan Selatan \\ Email : agustina.hotma@gmail.com
}

\begin{abstract}
Abstrak-Tujuan penelitian adalah untuk peningkatan dan pengendalian kualitas produksi yang melibatkan faktor manusia dan mesin pada PT.X. Metode penelitian yang digunakan adalah alat bantu pengedalian kualitas yaitu Diagram Pareto dan Peta Kendali $P$ untuk memudahkan dalam menganalisis penyebab kecatatan Produk Bolck Cylinder. Berdasarkan hasil penelitian yang telah dilaksanakan diketahui bahwa cacat yang sering terjadi adalah GH BlcShft cope $3 \& 4$, Scabing dan Gomi Drag. GH Blcshft cope $3 \& 4$ memiliki frekuensi kecacatan sebanyak 3,277 dengan presentase sebesar $40,6 \%$. Scabing memiliki frekuensi kecacatan sebanyak 1,900 dengan presentase sebesar 23,5\% sedangkan Gomi Drag memiliki frekuensi kecacatan sebanyak 1,580 dengan presentase sebesar 19,6\%.
\end{abstract}

Kata Kunci : Silinder Blok, Diagram Pareto, Peta Kendali P.

\section{PENDAHULUAN}

$\mathrm{P}$ engecoran saat ini merupakan salah satu proses manufaktur yang banyak digunakan di dunia industri. Hal ini disebabkan pengecoran memiliki beberapa keunggulan dibandingkan dengan metode manufaktur lainnya, antara lain: dapat memproduksi benda-benda yang bervariasi bentuk dan ukurannya, produk yang dihasilkan sedikit sekali yang terbuang (net-shape), prosesnya lebih fleksibel, dapat memproduksi secara massal, ekonomis, dan dapat digunakan untuk berbagai macam logam. Selain itu sifat mekanik dari material bisa diatur dengan penambahan elemen-elemen paduan lainnya. Karena banyak keunggulan itulah, pengecoran saat ini menjadi populer digunakan di dunia industri. Walaupun demikian, sejalan dengan berjalannya waktu dan usia peralatan, sering kali muncul produk-produk cacat yang tentu saja tidak diharapkan oleh industri manufaktur. Jumlah produk yang cacat diharapkan dapat diminimalisasi dengan menemukan akar permasalahan yang paling banyak menyebabkan produk cacat, dimana dapat diidentifikasi sedini mungkin penyebab terjadinya produk cacat untuk pencegahan terjadinya produk cacat.

Jenis cacat yang dihasilkan oleh perusahaan tersebut sangat berpengaruh terhadap hasil produksi yang telah ditetapkan karena merugikan dalam hal biaya produksi maupun waktu kerja. Presentase produk cacat yang dihasilkan dalam kurun periode tahun 2010 sampai 2015 sekitar 0,012. Adapun tujuan penelitian ini adalah untuk menganalisis kecacatan Produk Block Cylinder di PT. X.

\section{METODE PENELITIAN}

\section{Metode Penelitian}

Penelitian ini dilakukan di PT. X yang merupakan salah Satu perusahaan manufaktur di Indonesia. Produk yang diamati adalah Block Cylinder. Analisis pengendali kualitas yang digunakan adalah Peta Kendali (Control Chart) dan Diagram Pareto.

\section{Peta Kendali (Control Chart)}

Teori umum Control Chart pertama kali ditemukan oleh Dr. Walter A. Shewhart, dan Peta Kendali yang dikembangkan menurut asas-asas ini kerapkali dinamakan peta kendali Shewhart. Control Chart adalah grafik yang digunakan untuk menentukan apakah suatu proses berada dalam keadaan in control atau out control. Batas pengendalian yang meliputi batas atas (upper control limit) dan batas bawah (lower control limit) dapat membantu untuk menggambarkan performansi yang diharapkan dari suatu proses, yang menunjukkan bahwa proses tersebut konsisten.

Ada beberapa alasan menggunakan Control Chart yaitu sebagai berikut:

1. Control Chart adalah teknik yang telah terbukti guna meningkatkan produktivitas.

2. Control Chart efektif dalam pencegahan cacat.

3. Control Chart mencegah penyesuaian proses yang tidak perlu.

4. Control Chart memberikan informasi diagnostik.

5. Control Chart memberikan informasi tentang kemampuan proses.

6. Control Chart memanfaatkan data proses yang ada yang dikumpulkan secara berkala dan memberikan informasi ini dalam suatu format yang berguna untuk manajemen dalam pencegahan cacat

Persamaan untuk Control Chart

$C L=\bar{p}=\frac{X}{N}$

$U C L=\bar{p}+3 \sqrt{\frac{\bar{p}(1-p)}{n}}$

$L C L=\bar{p}-3 \sqrt{\frac{\bar{p}(1-p)}{n}}$

Keterangan:

$\mathrm{CL} / \bar{p}=$ Titik Tengah 


$$
\begin{aligned}
& \mathrm{UCL}=\text { Batas Kontrol Atas } \\
& \mathrm{LCL}=\text { Batas Kontrol Bawah } \\
& \mathrm{X}=\text { Total Cacat } \\
& \mathrm{N}=\text { Total Produksi } \\
& \mathrm{n} \quad=\text { Jumlah Sampel }
\end{aligned}
$$

\section{Diagram Pareto}

Diagram Pareto adalah grafik batang yang menunjukkan masalah berdasarkan urutan banyaknya kejadian [6]. Di namakan Diagram Pareto sesuai dengan penemunya seorang bangsa Italia bernama Wilfredo Pareto pada tahun 1897. Dalam Diagram Pareto dikenal istilah "Vital Few-Trivial Many", yang artinya sedikit tapi vital atau sangat penting, banyak tetapi kurang vital atau hasilnya kurang penting [13].

Ada empat langkah pembuatan Diagram Pareto adalah menentukan hal-hal apa yang akan diteliti dan cara untuk mengumpulkan data, menyusun kembali data lembar periksa, membuat diagram batang dari data yang ada, memberi penjelasan pada Diagram Pareto [13].

\section{Metode Pengambilan Data}

1. Data Primer

Data primer diperoleh dari pengukuran langsung di lapangan (studi lapangan). Data primer dalam penelitian ini berupa data produk Block Cylinder. Studi lapangan dilakukan dengan cara wawancara dan kuesioner yaitu pengumpulan data dengan mengajukan pertanyaan secara langsung baik secara lisan maupun tulisan kepada pihak terkait dan pengamatan langsung terhadap obyek yang diteliti serta data kecatatan Block Cylinder.
2. Data Sekunder

Data sekunder diperoleh melalui studi pustaka merupakan suatu tahapan untuk mendapatkan informasi-informasi yang digunakan sebagai dasar pemikiran dalam penelitian ini yang selanjutnya digunakan sebagai acuan dan literatur dasar untuk memecahkan masalah yang terjadi. Studi kepustakaan dilakukan dengan cara membaca dan memahami buku-buku, literatur, referensi dan lain sebagainya yang berkaitan dengan penelitian ini yaitu peta kendali dan diagram pareto.

\section{Peralatan Penelitian}

1) Camera Smartphone Iphone $5 \mathrm{~S}$ dengan memory penyimpanan $5 \mathrm{~GB}$.

2) Produk Block Cylinder

3) Data Cacat Produk Block Cylinder tahun 2010 - 2015

4) Microsoft Visio 2007

5) Microsoft Excel 2013

6) Minitab 17

\section{HASIL DAN PEMBAHASAN}

PT. X berada di Kota Jakarta memproduksi 2 jenis Block Cylinder. Block Cylinder 1TR untuk produk mobil Kijang Innova dan Block Cylinder 2TR untuk Toyota Kijang Innova Diesel dan Toyota Fortuner. Berikut adalah perbandingan jumlah kecacatan Block Cylinder 1TR dan 2TR:

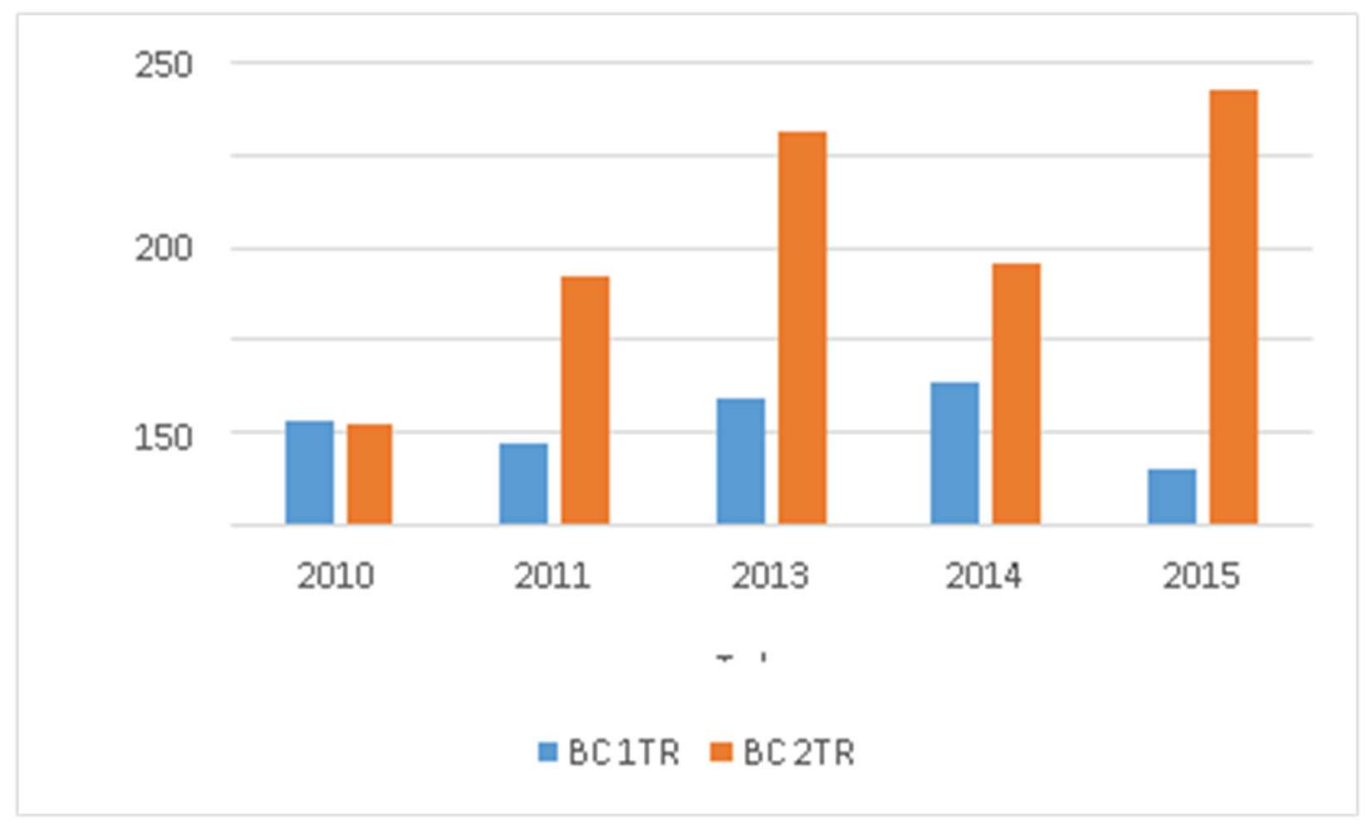

Gambar 1. Perbandingan Cacat Block Cylinder

Dari gambar di atas terlihat bahwa Block Cylinder 2TR memiliki nilai kecacatan tertinggi dibandingkan Block Cylinder 1TR.. Penelitian ini akan membahas lebih detail tentang Block Cylinder 2TR. Pada tahap pengumpulan data, data-data yang dikumpulkan meliputi data primer yaitu data kecacatan Produk Block Cylinder 2TR (2700cc) tahun 2010 sampai 2015. Berikut adalah gambar produk Block Cylinder 2TR (2700cc) : 


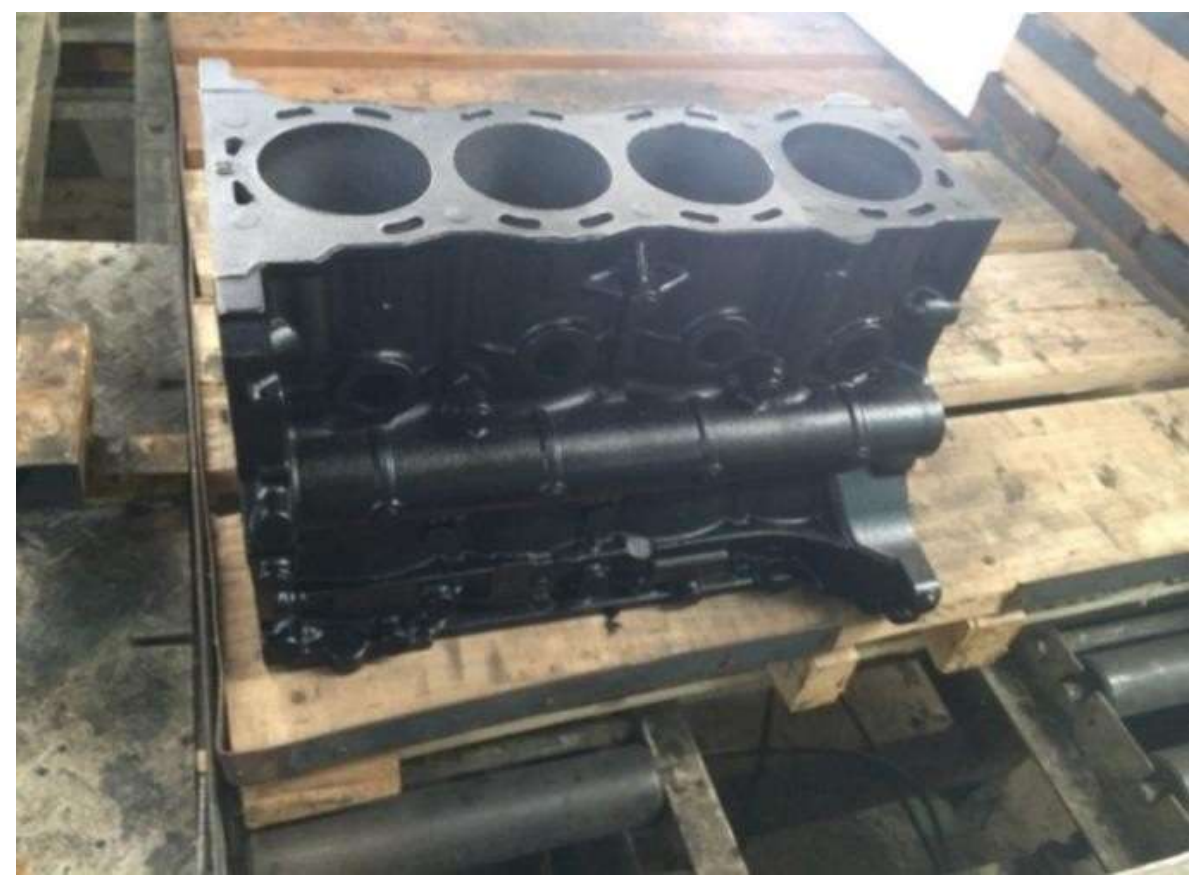

Gambar 2. Block Cylinder 2TR

Setelah semua data terkumpul selanjutnya adalah mengolah data dengan menggunakan Diagram Pareto, Peta Kendali P dan Diagram Fishbone.

\section{Diagram Pareto}

Langkah awal dalam penerapan metode ini adalah dengan menggunakan Diagram Pareto. Berdasarkan data cacat Produk Block Cylinder 2TR (2700cc) Tahun 2010-2015 yang didapat, jenis cacat yang paling sering dijumpai adalah jenis cacat $\mathrm{GH}$ BlcShft Cope $3 \& 4$ dimana GH Blcshft cope $3 \& 4$ memiliki frekuensi kecacatan sebanyak 3,277 dengan presentase sebesar 40,6\%. GH BlcShft Cope 3 \& 4 merupakan jenis cacat yang berasal dari proses penuangan cairan, cacat ini disebabkan oleh pengaruh temperatur didalam tungku (ladle) melebihi standar yaitu $1410 \pm 5 \mathrm{OC}$ dimana ketika temperatur tinggi menyebabkan hasil produk lambat untuk terbentuk dan ketika temperatur rendah hasil produk akan keropos dan juga disebabkan proses penuangan yang terputus-putus dan waktu proses penuangan juga mempengaruhi hasil kualitas produk. Adapun gambar data cacat dapat di lihat pada Gambar 3.

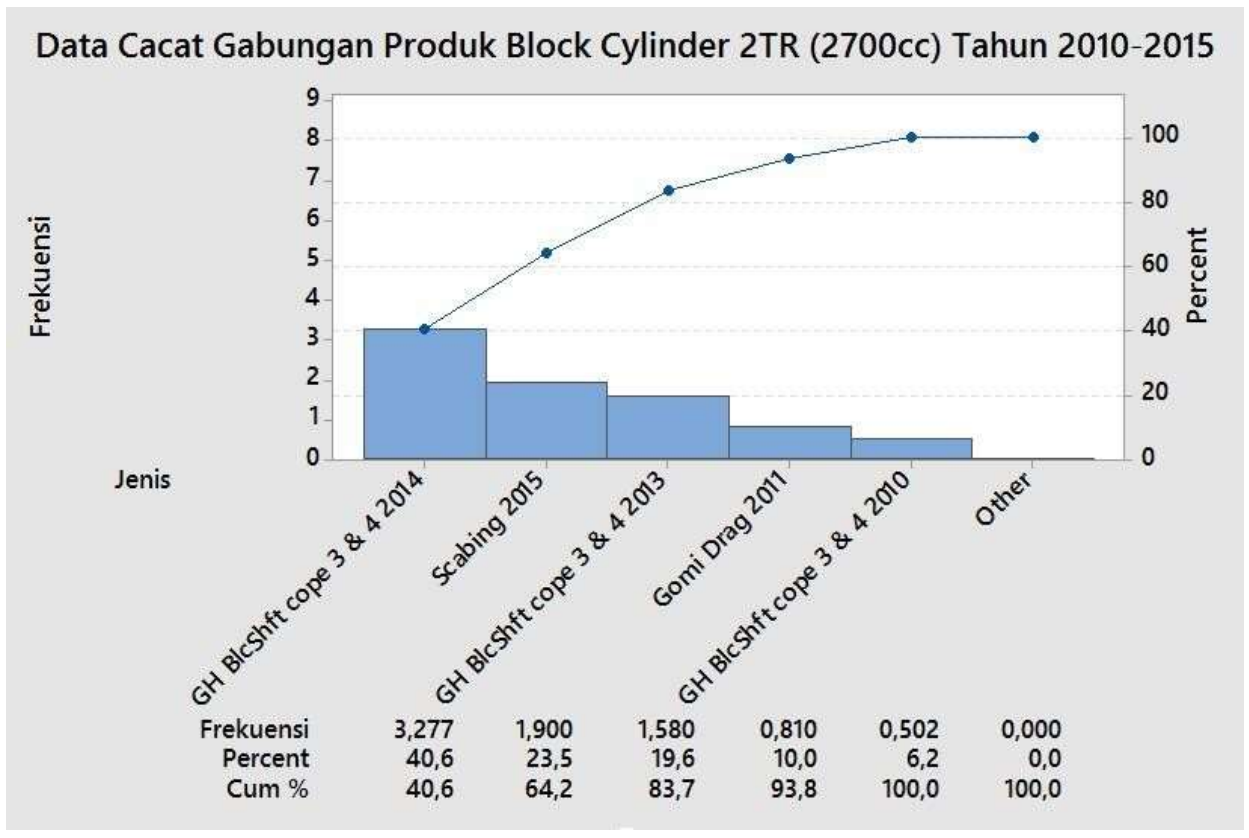

Gambar 3. Diagram Pareto Produk Bolock Cylinder 2TR berdasarkan Tingkat Kecatatan Tahun 2010-2015 


\section{Control Chart P}

Setelah menggunakan Diagram Pareto, analisis data kecacatan dibuat dengan menggunakan Peta Kendali P. Peta Kendali berfungsi untuk mengendalikan proporsi dari itemitem yang tidak memenuhi syarat spesifikasi kualitas atau proporsi dari produk yang cacat yang dihasilkan dalam suatu proses. (Vincent, 1998, p149), Peta Kendali yang dipakai adalah Peta Kendali atribut karena datanya bersifat kualitatif yang dapat dihitung untuk pencatatan dan analisis, maka dipilihlah Peta Kendali p untuk menujukkan proporsi cacat dalam tiap subgrupnya dan diambil salah satu sampel untuk memasukkan rumusnya adapun rumus untuk menentukan perhitungan Center Line (CL), Upper Control Limit (UCL) dan Lower Control Limit (LCL) pada Peta Kendali P adalah sebagai berikut:

Penentuan perhitungan untuk Center Line (CL) adalah sebagai berikut:

$C L=p=\frac{x}{n}=\frac{7627}{633936}=0,012$
Perhitungan Upper Control Limit (UCL) adalah sebagai berikut:

$$
\begin{aligned}
& U C L=\bar{p}+3 \sqrt{\frac{\bar{p}(1-\bar{p})}{n}} \\
& U C L=0,012+3 \sqrt{\frac{0,012(1-0,012)}{57}}=0,055
\end{aligned}
$$

Perhitungan Lower Control Limit (LCL) adalah sebagai berikut:

$$
\begin{aligned}
& U C L=\bar{p}-3 \sqrt{\frac{\bar{p}(1-\bar{p})}{n}} \\
& U C L=0,012-3 \sqrt{\frac{0,012(1-0,012)}{57}}=-0,031
\end{aligned}
$$

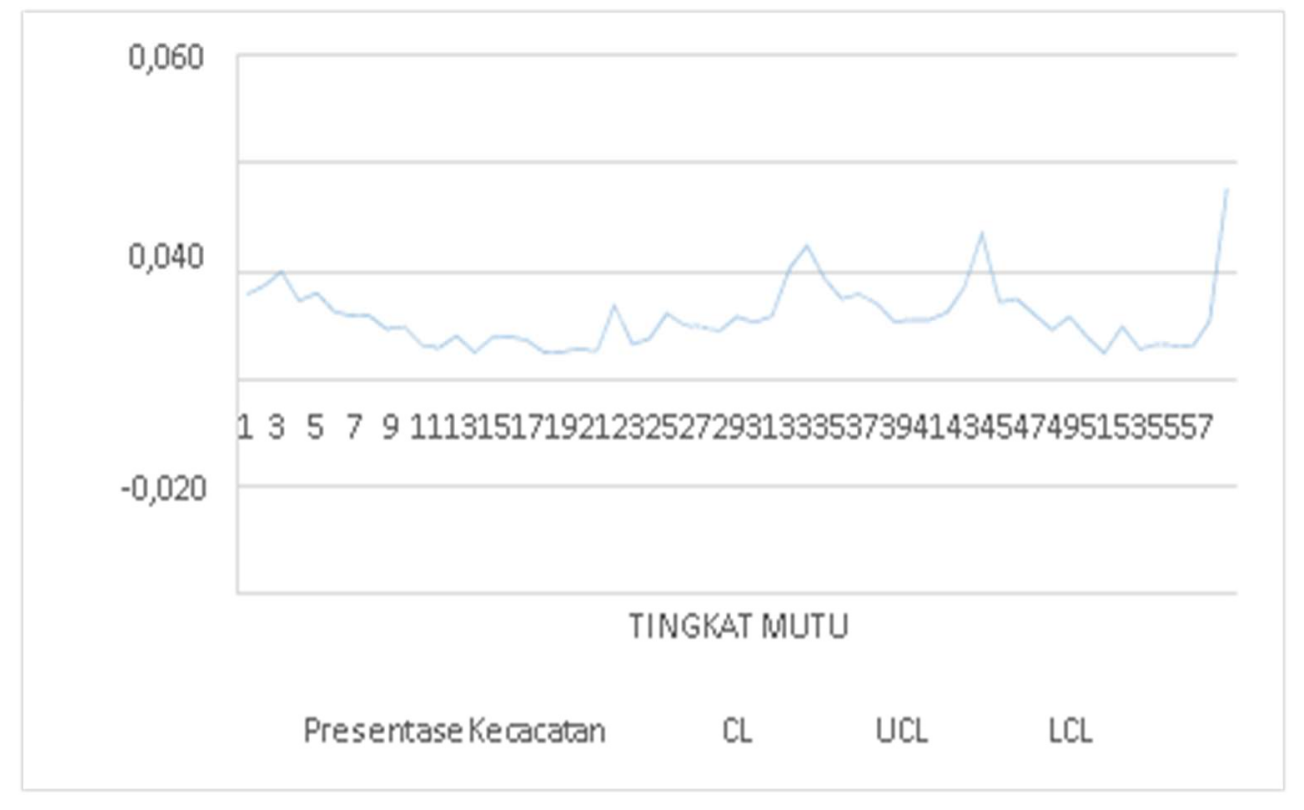

Gambar 4. Diagram Mutu Jenis Kategori GH BlcShft cope $3 \& 4$

Dari gambar di atas terlihat bahwa kecacatan pada Block Cylinder 2TR Tahun 2010-2015 ini terdapat beberapa nilai yang cukup tinggi tetapi nilai yang mengalami peningkatan signifikan pada periode 57 dimana memiliki nilai yaitu sebesar 0,04 , nilai ini dipengaruhi oleh hasil dari pembagian antara total cacat yaitu sebesar 322 dibagi dengan total produksi yaitu sebesar 11874 dan dapat disimpulkan bahwa walaupun ada terdapat nilai yang lebih tinggi yaitu pada periode 7 namun data terseuat masih berada pada sebaran data normal dan tidak melewati ambang batasnya (out of control).berada pada sebaran data normal dan tidak melewati ambang batasnya (out of control).

Berdasarkan pengolahan data Tahun 2010 - 2015 yang telah dilakukan, diketahui bahwa tidak terdapat data proporsi kecacatan produk yang keluar dari batas kendali atas maupun batas kendali bawah tetapi pada minggu ke 51 terdapat tingkat mutu yang bernilai lebih tinggi dari yang lain.

\section{Regulasi untuk perusahaan ke depan}

Berdasarkan penelitan yang telah dilakukan, peneliti memberikan saran ataupun masukan kepada perusahaan sehingga cacat yang terjadi dapat diminimalisir ataupun dikurangi pada ketika proses produksi sedang berlangsung pada saat mendatang. Dilihat dari faktor manusianya adalah operator perlu memeriksa kembali temperature sebelum proses penuangan serta memeriksa kembali pada saat pemberian pasir. 
Dilihat dari faktor material adalah operator perlu memeriksa kembali pada saat pemberian air dan standar suhu sebesar $1410 \pm 5^{\circ} \mathrm{C}$. Filihat dari faktor mesin adalah adanya standar pengecekan dan perbaikan mesin minimal 8 jam kerja. Dilihat dari faktor metode yaitu standarnya adalah penuangan sebanyak 15 flask, pada proses penuangan 1-10 posisi jarak bibir ladel ke pouring cup jauh sedangkan pada proses 11-15 sebaliknya.

\section{KESIMPULAN}

Dari hasil-hasil penelitian dan pembahasan hasil kecacatan Produk Block Cylinder pada tahun 2010 - 2015 adalah sebagai berikut:

1. Cacat yang sering terjadi adalah GH BlcShft cope $3 \& 4$, Scabing dan Gomi Drag.

2. GH Blcshft cope $3 \& 4$ memiliki frekuensi kecacatan sebanyak 3,277 dengan presentase sebesar 40,6\%.

3. Scabing memiliki frekuensi kecacatan sebanyak 1,900 dengan presentase sebesar 23,5\% sedangkan Gomi Drag memiliki frekuensi kecacatan sebanyak 1,580 dengan presentase sebesar $19,6 \%$.

\section{DAFTAR PUSTAKA}

[1] _ _ "Control Chart". https://www.opexresources.com. Diakses pada tanggal 8 Maret 2016.

[2] Afandi, Taufik. Diagram Pareto. https://taufikandii.blogspot.co.id, 2015. Diakses pada tanggal 15 Desmber 2015

[3] Ahyari, Agus. 2002. Manajemen Produksi Pengendalian Produksi. Yogyakarta, BPFE- Anggota IKAPI.

[4] Feigenbaum, A.V, 1992. Kendali Mutu Terpadu. Penerbit Erlangga. Jakarta.
[5] Gaspersz, Vincent. 1998. Production Planning and Inventory Control. Jakarta: Gramedia Pustaka Utama.

[6] Gasperz, V., 2003. Metode Analisis Untuk Peningkatan Kualitas. PT Gramedia Pustaka Utama, Jakarta.

[7] Gasperz, Vincent. 2001. Total Quality Manajemen. Penerbit PT. Gramedia Pustaka Utama.Jakarta

[8] Gasperz, Vincent. 2005. Total Quality Management. Jakarta, PT. Gramedia Pustaka Utama

[9] Haming, Murdifin dan Mahfud Nurnajamuddin. 2007. Manajemen Produksi Modern: Operasi Manufaktur dan Jasa. Jakarta, PT Bumi Aksara..

[10] Heizer, Jay and Barry Render. 2006. Operations Management (Manajemen Operasi). Jakarta, Salemba Empat.

[11] Kurnadi, Muhammad Marsudi, Yassyir Maulana. 2020. Analisis Pengendalian Produk Cacat Pada Kayu Lapis Menggunakan SQL (Statistical Quality Control) Pada Pabrik PT. Wijaya Tri Utama Plywood Industry. Journal of Industrial Engineering and Operation Managemen (JIEOM), Vol.03, No.02, pp. 12-16.

[12] Kusnadi, Eris. Fishbone. https://eriskusnadi.wordpress.com.html. 2011. Diakses pada tanggal 15 Desember 2015

[13] Kuswadi, 2004., Cara Mengukur Kepuasan Karyawan. Penerbit PT. Elex Media Komputindo, Jakarta.

[14] Lawrence M. Corbett and Kate N. Rastrick, 2000. Quality performance and organizational culture: A New Zealand study, International Journal of Quality \& Reliability Management, Vol. 17, No. 1, pp. 14-26.

[15] Montgomery, Douglas C. 2001. Introduction to Statistical Quality Control. 4th Edition. New York, John Wiley \& Sons, Inc.

[16] Nasution, M. N. 2005. Manajemen Mutu Terpadu. Bogor, Ghalia Indonesia.

[17] Prawirosentono, Suyadi. 2007. Filosofi Baru Tentang Manajemen Mutu Terpadu Abad 21 "Kiat Membangun Bisnis Kompetitif". Jakarta, Bumi Aksara.

[18] Richard B. Chase, Nicholas J. Aquilano and F. Robert Jacobs. 2001. Operations Management For Competitive Advantage. 9th Edition. New York, Mc Graw-Hill Companies.

[19] Sila, I. 2007. Examining the effects of contextual faktors on TQM and performance through the lens of organizational theory: an empirical study, Journal of Operations Management, Vol. 25, No. 1, pp. 83-109.

[20] Smith, Gerald M., (1998). Statistical Process Control and Quality Improvement, Prentice Hall New Jersey.

[21] Sofjan Assauri. 1998. Manajemen Operasi Dan Produksi. Jakarta : LP FE UI.

[22] Tjiptono, Fandy Dan Diana, Anastasia. 2001. Total Quality Manajemen Edisi Revisi. Penerbit ANDI. Yogyakarta. 